\title{
A articulação entre teoria e prática na formação de professores na perspectiva das Arquiteturas Pedagógicas
}

\author{
Rosane Aragón ${ }^{1}$, Luciana B. Turchielo ${ }^{2}$, Aline Verardo Corrêa ${ }^{3}$ \\ ${ }^{1}$ Faculdade de Educação - Programa de Pós-graduação em Educação (PPGEDU), \\ UFRGS, Porto Alegre, RS \\ ${ }^{2}$ Instituto Multidisciplinar - Universidade Federal Rural do Rio de Janeiro (UFRRJ), \\ Nova Iguaçu, RJ. \\ ${ }^{3}$ Programa de Pós-graduação em Educação (PPGEDU), UFRGS, Porto Alegre, RS. \\ \{rosane.aragon, \{lucianabt14\}, \{alineverardo2\} egmail.com\}
}

\begin{abstract}
This paper discusses the articulation between theory and practice, in a Pedagogy Course, in the distance modality offered by a public university in the southern region of Brazil. Among the strategies adopted in the course to promote this articulation, we highlight the use of Pedagogical Architectures. The research focused on academic publications, with the main objective of analyzing how this topic was treated. In the interpretation and analysis of the data, the content analysis technique was applied in 30 scientific articles, considering two categories: 1) theoretical comprehension processes, and 2) reports of changes in pedagogical practices, considering the pedagogical architectures approach. The results indicate that there have been significant changes in teacher training based on the pedagogical proposal of the course. These proposals contributed to the teachers to start acting with more reflective practices.
\end{abstract}

Resumo. Este trabalho discute a articulação entre teoria e prática, em um Curso de Pedagogia, na modalidade a distância, ofertado por uma universidade pública da região sul do Brasil. A pesquisa concentrou-se em publicações acadêmicas, com o objetivo principal de analisar como essa temática foi tratada. Na interpretação e análise dos dados, foi aplicada a técnica de análise de conteúdo em 30 artigos científicos, considerando duas categorias: 1) processos de compreensão teórica, e 2) relatos de mudanças nas práticas pedagógicas, considerando a abordagem das arquiteturas pedagógicas. Os resultados indicam que ocorreram mudanças significativas na formação de professores a partir da proposta pedagógica do curso. Essas propostas atuaram de forma a colaborar para que os profissionais tenham alcançado práticas mais reflexivas. 
VII Congresso Brasileiro de Informática na Educação (CBIE 2018)

Anais dos Workshops do VII Congresso Brasileiro de Informática na Educação (WCBIE 2018)

\section{Introdução}

As reflexões a seguir originaram-se a partir do projeto de pesquisa intitulado Concepções e Práticas dos Cursos de Pedagogia a Distância das Universidades Federal do Rio Grande do Sul (UFRGS) e da Universidade Federal de Pelotas (UFPEL). O problema de pesquisa em questão foi elaborado com o intuito de entender: Como as concepções de formação dos cursos de pedagogia a distância da UFRGS e da UFPEL foram traduzidas em práticas pedagógicas? Objetivou-se com essa pesquisa compreender as concepções pedagógicas dos cursos e suas relações com as práticas. A pesquisa considerou as seguintes temáticas para aprofundamento do estudo: articulação entre teoria e prática; atuação e relação dos professores, tutores e alunos; avaliação diagnóstica e formativa/ avaliação do curso; organização curricular interdisciplinar; estratégias e arquiteturas pedagógicas; recursos; práticas orientadas e reconstruídas; compreensões sobre o modelo de curso pelos alunos e processos de aprendizagem.

O presente artigo visa analisar, a partir das publicações em periódicos, como os alunos-professores desenvolveram articulações entre as teorias estudadas e as práticas pedagógicas, no contexto do curso de formação a distância da UFRGS que usa as tecnologias digitais na perspectiva das arquiteturas pedagógicas.

\section{A relação teoria e prática na formação docente}

São muitas as abordagens que tratam das questões que envolvem o desafio de articular teoria e prática nos cursos de formação de professores. Cabe às instituições formadoras, operacionalizar o pressuposto da articulação entre teoria e prática, que deverá ocorrer de forma integrada e de diferentes modos, ao longo do processo de formação, com o desenvolvimento dos conhecimentos e habilidades necessários ao exercício da docência. Nesse sentido, a proposta da relação teoria e prática é que esteja presente nos conhecimentos específicos e pedagógicos, nas concepções didático-pedagógicas, e que seja aliada às práticas e às experiências vivenciadas, nas escolas de educação básica, durante 0 processo de formação do futuro professor (Brasil, 2015).

Freire (2011), ao tratar desse enfoque, diz que o curso de formação deve transformar-se numa experiência que seja um verdadeiro trabalho intelectual. Nesse processo de formação, a teoria e a prática tem como finalidade a compreensão da realidade e, se possível, transformação dessa realidade. Em documento elaborado pela GATE (Global Alliance For Transforming Education, 1990) é igualmente reafirmada a interdependência inerente da teoria, a investigação e a prática em constante evolução, dentro da visão de educação holística. Se não, a relação teoria e prática tende a se resumir a um jogo de ideias, não atingindo a verdadeira formação.

A reflexão crítica e a pesquisa científica são fundamentais para ampliar as possibilidades no ensino e nas práticas educativas nos currículos dos cursos de licenciatura, em uma estreita relação entre teoria e prática. "A reflexão crítica sobre a prática se torna uma exigência da relação teoria/prática sem a qual a teoria pode ir virando blábláblá e a prática, ativismo" (Freire, 1996, p.22).

Nessa perspectiva, conforme Nóvoa (2001), o professor que assume a sua própria realidade escolar como um objeto de pesquisa e de reflexão, ao refletir sobre a sua prática, ao pensar, elabora em cima da mesma, cria novas possibilidades de ensino e aprendizagem. 
VII Congresso Brasileiro de Informática na Educação (CBIE 2018)

Anais dos Workshops do VII Congresso Brasileiro de Informática na Educação (WCBIE 2018)

O pressuposto de articulação entre teoria e prática pedagógica foi corroborado nas publicações analisadas nesta pesquisa. E, a inserção do graduando em práticas na escola de educação básica, durante todo o curso de graduação, com a intenção de levá-lo a compreender e estabelecer as relações entre teoria e prática.

\section{Contextualizando brevemente o curso}

A delimitação e o enfoque do estudo têm como foco principal a formação de professores, na modalidade a distância, ofertados por uma universidade pública da região sul do Brasil. O curso de Pedagogia a distância (PEAD) UFRGS integra o contexto de expansão e crescimento de cursos de formação de professores a distância no Brasil, estando atrelado às políticas de fomento do governo federal, principalmente da última década.

O Curso PEAD destinou-se a professores em serviço na Educação Infantil e nos Anos Iniciais do Ensino Fundamental, sem habilitação em nível superior e com efetivo exercício em escolas públicas estaduais e municipais do Estado do Rio Grande do Sul (RS). Ofertou 400 vagas distribuídas nos municípios do Estado do RS- que disponibilizaram os polos de apoio presencial para o desenvolvimento do curso. Foi ofertado no âmbito do programa Pró-licenciatura do Ministério da Educação (MEC). O PEAD iniciou em 2006/2 e terminou em 2011/1. O Curso foi desenvolvido em nove eixos articuladores, cada um deles correspondendo a um semestre letivo. Para garantir as articulações entre os componentes curriculares e a ligação com as experiências de cada aluno em sala de aula, em cada eixo é desenvolvido o Seminário Integrador.

O projeto pedagógico do Curso propõe um modelo de formação que busca superar a distância existente entre a teorização de práticas educacionais e a vivência destas práticas em sala de aula. Tal diferenciação do Curso PEAD para outros cursos de Pedagogia foi necessária, principalmente, por dois motivos: (I) os alunos do curso foram professores em exercícios da rede pública sem formação específica e (II) o curso buscou considerar as experiências de vida e profissionais dos professores, garantindo qualidade na formação.

O curso a distância apresenta como um importante diferencial o uso intensivo de tecnologias digitais para a mediação pedagógica e as arquiteturas pedagógicas convergindo na aproximação da realidade escolar, gerando autonomia na aprendizagem dos alunos, bem como o protagonismo, onde a teoria e a realidade se interconectam.

Devido à aproximação do graduando de Pedagogia com a realidade escolar, abre-se a possibilidade de não se restringir o contato do aluno apenas ao período de estágio. Diferentemente do que ocorria em cursos de formação de professores no modelo $3+1$ (3 primeiros anos de teoria e o último ano de prática), em que o contato com a realidade acaba sendo exclusivamente no período dos estágios e, normalmente, encontram-se mais ao final dos cursos de graduação. Assim, limitando as possibilidades de ensino e aprendizagem dos graduandos e a dicotomia das relações teoria e prática durante a formação acadêmica.

No recorte desta pesquisa, no decorrer do curso analisado, observamos a aproximação da universidade e a realidade escolar favorecendo a possibilidade de poder 
VII Congresso Brasileiro de Informática na Educação (CBIE 2018)

Anais dos Workshops do VII Congresso Brasileiro de Informática na Educação (WCBIE 2018)

interligar a realidade das escolas e salas de aula ao seu entorno com as teorias da educação estudadas na universidade.

\section{As arquiteturas pedagógicas}

As Arquiteturas pedagógicas são definidas, dentro da perspectiva da ecologia cognitiva (LEVY, 1990) como suportes estruturantes para as aprendizagens. Conforme Carvalho, Nevado e Menezes (2007), as arquiteturas são constituídas por uma rede que envolve epistemologias relacionais, pedagogias abertas, tecnologias digitais, novos referenciais de tempos e espaços de aprendizagem.

A ideia consiste em se pensar em abordagens pedagógicas estruturantes, baseada nos princípios da Epistemologia Genética de Jean Piaget (1973) e da Pedagogia da Pergunta de Paulo Freire (1999), apoiada nos mecanismos de comunicação e interação propiciada pela cultura digital.

As arquiteturas, conforme Nevado, Menezes e Vieira Júnior, (2011) pressupõem pesquisa, aprofundamento das relações entre a teoria e a prática, atividades interativas e autorais suportadas por tecnologias e abordagens problematizadoras por parte do professor. Elas propõem aos estudantes protagonismos e atitudes reflexivas.

Conforme Aragón (2016) as arquiteturas visam dar às tecnologias digitais sentidos que ultrapassem o seu uso periférico e dissociado das práticas pedagógicas, a fim de explorar novas possibilidades de referenciamento dos espaços e tempos, transpondo os limites tradicionais das instituições educativas e modificando os papéis e as formas de mediação, oferecendo assim suportes estruturantes para as construções individuais e coletivas.

\subsection{A Arquitetura Pedagógica Portfólio de Aprendizagem}

Os estudantes do curso foram convidados a construir um registro de suas aprendizagens relevantes, identificadas no seu cotidiano, originadas durante suas práticas, nas quais buscavam a inovação a partir da articulação de suas experiências com o aporte dos novos suportes teóricos. A proposta tinha por finalidade incentivar a produção textual e mostrar o papel que ela desempenha em duas metas importantes: a formação do professor reflexivo e a construção de redes de aprendizagem. Durante o desenrolar de cada semestre letivo os estudantes postavam relatos de suas aprendizagens, identificando evidências e construindo argumentos. Os mediadores davam suporte pelos questionamentos levantados que serviam de instrumento para as reflexões e reconstruções. Ao final de cada semestre, os estudantes usavam essas postagens para construir um documento denominado Síntese Reflexiva das Aprendizagens. Após lidos e revisados, uma versão final era produzida e apresentada em bancas de avaliação, nos workshops de finais de cada semestre, na interdisciplina intitulada Seminário Integrador.

\section{Metodologia}

Em termos metodológicos, os procedimentos utilizados seguiram uma abordagem de pesquisa qualitativa, cujo interesse centrou-se em compreender os significados das publicações sobre o curso de Pedagogia da UFRGS, na perspectiva de como os autores trataram da articulação entre teoria e prática. 
VII Congresso Brasileiro de Informática na Educação (CBIE 2018)

Anais dos Workshops do VII Congresso Brasileiro de Informática na Educação (WCBIE 2018)

$\mathrm{Na}$ organização dos dados, utilizou-se o software de apoio à pesquisa qualitativa NVivo. O objetivo foi contribuir para a solução do problema de pesquisa, ou seja, de que forma a relação teoria e prática foi abordada na concepção dos projetos pedagógicos e qual proposta metodológica foi operacionalizada nesta relação. Buscou-se, nos relatos dos sujeitos, principalmente dos alunos-professores, elementos implicados na vivência tanto no curso de formação como na prática da escola. Assim, procedeu-se à análise categorial, corroborando com o problema em questão.

Num primeiro momento, a ideia geral foi dividida em unidades de análise que decompõe: como a teoria incide na prática e como a prática incide na teoria nos cursos. Procura-se, assim, evidenciar o que significa articular teoria e prática, ou, dito de outra forma, como modificar a prática e como ressignificar a teoria.

Num segundo momento, as unidades da "articulação teoria e prática" foram divididas em duas subcategorias. Os descritores que compõem são respectivamente: subcategoria (1) Menção ou relatos como decorrência de construções teóricas, e subcategoria (2) Menção/considerações sobre processos de compreensão (significado teórico) de situações de sala de aula por parte das alunas. Após os dados foram novamente agrupados em função dos propósitos da investigação.

$\mathrm{Na}$ pesquisa realizada, foram encontrados 30 artigos que apresentam 75 referências do descritor da subcategoria 1 (significado teórico). Representando mais da metade dos artigos analisados, a forma como são trabalhadas as questões teóricas na formação das alunas de Pedagogia demonstra ser um aspecto que se destaca nos cursos, conforme demonstra o quadro abaixo.

Quadro 1. Relação entre os assuntos/tema com o quantitativo de artigos

\begin{tabular}{|l|c|}
\hline \multicolumn{1}{|c|}{ Assuntos recorrentes nos artigos } & Número de artigos \\
\hline $\begin{array}{l}\text { Utilização da prática docente para } \\
\text { estudar a teoria }\end{array}$ & 12 \\
\hline $\begin{array}{l}\text { Caminhos metodológicos utilizados para } \\
\text { trabalhar a teoria }\end{array}$ & 4 \\
\hline $\begin{array}{l}\text { Planejamento de atividades aos alunos } \\
\text { de escola para praticar a teoria }\end{array}$ & 6 \\
\hline $\begin{array}{l}\text { Emprego da tecnologia com } \\
\text { transposições didáticas }\end{array}$ & 5 \\
\hline $\begin{array}{l}\text { Teoria aplicada ou vivenciada: atuação } \\
\text { ou observação de um professor, } \\
\text { analisando a relação teoria e prática }\end{array}$ & 3 \\
\hline
\end{tabular}


VII Congresso Brasileiro de Informática na Educação (CBIE 2018)

Anais dos Workshops do VII Congresso Brasileiro de Informática na Educação (WCBIE 2018)

Na subcategoria 2, foram encontrados, em 11 artigos um total de 19 referências. As menções de mudanças nas práticas são em número menor devido à dificuldade de se acompanhar as alunas em sua atuação após o curso. Portanto, as considerações acabaram mais atreladas ao transcorrer do curso ou ao final através das avaliações das cursistas.

$\mathrm{Na}$ interpretação e análise dos dados, foi aplicada a técnica de análise de conteúdo. Ela consiste em extrair dos textos os conteúdos mais importantes e buscar o sentido contido, de maneira a compreender os elementos presentes e ausentes, neste caso, no conteúdo dos textos dos autores. Segundo Bardin (2011, p.44), a definição desta metodologia é entendida como "[...] um conjunto de técnicas de análise das comunicações que utiliza procedimentos sistemáticos e objetivos de descrição do conteúdo das mensagens".

A seguir, apresentam-se os resultados que foram identificados na análise geral da articulação entre teoria e prática, bem como as diferentes abordagens atribuídas pelos autores dos textos.

\section{Análise: da teoria à prática}

\subsection{Relatos de apropriação teórica}

Nos artigos investigados, os autores abordam a preocupação em estabelecer relações entre a metodologia utilizada e a tecnologia, proporcionando às alunas atividades que fossem instigadoras ou que trouxessem novas ferramentas e formas de interagir. No curso PEAD, a tomada de consciência foi desencadeada apresentando atividades que as alunas ainda não tinham domínio total, mas com uma proposta pedagógica engajada, gerando reflexão na busca das relações teóricas, conforme o relato de uma aluna.

No curso, sempre houve uma orientação para que tentássemos ver as mesmas coisas de outro modo, quebrando paradigmas, questionando as velhas certezas, aprendendo a distinguir concepções ingênuas dos saberes científicos. (...). Não havia uma conexão entre o que estava sendo desenvolvido no curso e a minha prática docente. Com o tempo, com o suporte e a orientação dos(as) professores(as) do PEAD, fui me dando conta de sempre fazer links entre teoria e prática (Al. VI) (COSTA; MAGDALENA, 2013).

As alunas foram instigadas a pensar sob novas perspectivas, estabelecendo ligação com sua atuação como professoras em sala de aula. No entanto, desenvolver a reflexão não é uma tarefa fácil, existiam alguns entraves, no início do curso, na questão de realmente estabelecer ligações entre a teoria e a prática, conforme indicam as docentes do PEAD.

A partir da análise do material escrito pelos alunos, destacamos que os mesmos vacilavam muito ao expor suas ideias, principalmente quando deviam relacionar suas experiências com a contribuição dos teóricos estudados. Ao relatarem sua caminhada profissional, detinham-se mais em aspectos pessoais, emocionais, descritivos, em detrimento de uma reflexão crítica sobre as práticas de sala de aula (CARRASCO, TRAINOTTI, 2013) 
VII Congresso Brasileiro de Informática na Educação (CBIE 2018)

Anais dos Workshops do VII Congresso Brasileiro de Informática na Educação (WCBIE 2018)

O processo de dar-se conta de suas aprendizagens no PEAD foi sendo registrado principalmente no portfólio de aprendizagem. Também, era registrado a dificuldade em articular teoria e prática, pois as alunas utilizavam o portfólio de aprendizagem mais para o relato de suas questões pessoais do que propriamente para refletir e estabelecer essas relações.

No decorrer do curso, a proposta pedagógica na sua intencionalidade, considerava o público de alunos-professores, propiciando condições para que este pudesse problematizar e refletir sobre como as relações pedagógicas ocorrem na realidade, e de que forma são pensadas e estruturadas as ações, estabelecendo ligações com os pressupostos teóricos.

Os professores formadores do curso buscaram trabalhar com problematização de fatos da vida escolar, realizando análises sob o enfoque teórico, estabelecendo conexões, instigando os alunos dos cursos à pesquisa, partindo de indagações e questionamentos das situações vivenciadas. Bem como solicitaram que, durante o curso, os alunosprofessores fizessem registros, por escrito, no portfólio de aprendizagem, a fim de socializar os conhecimentos construídos no decorrer dos semestres.

Conforme os extratos encontrados e selecionados nos textos analisados, os alunos foram se apropriando da escrita reflexiva, além de conseguirem estabelecer ligações entre a teoria e a prática vivenciada em sala de aula, através do incentivo das interdisciplinas, demonstrando a ocorrência de uma tomada de consciência.

A realização de um portfólio integrando minhas aprendizagens
fez com que me desse conta de quanto eu já havia mudado
meus conhecimentos - tecnológicos ou não - e o quanto a
minha prática já havia sido influenciada por isso. (Aluno 3)"
Conforme nos indica o aluno 3, ocorreu uma integração do
portfólio com a sua aprendizagem (ZEIDE et. al, 2013).

Através da escrita no portfólio, os alunos foram levados a ter a percepção da teoria influenciando a sua prática, como percebe-se pelas considerações do aluno 3, quando verbaliza a sua tomada de consciência, suas reflexões e percepções, de acordo com a citação das autoras.

O curso oportunizou a escrita reflexiva como uma estratégia para desenvolver o processo de compreensão do significado teórico, bem como lançaram desafios em relação à aprendizagem e à solução de problemas. Além de que alguns dos desafios estavam relacionados a colocar em prática o embasamento teórico de forma a estabelecer conexões com a realidade. Ao dar ênfase à elaboração de atividades de ensino, os docentes do curso estimularam as alunas a ponderarem sobre quais as suas concepções e, consequentemente, as teorias que suscitaram para organizarem as atividades, bem como a refletir a respeito do que é ensinar. Assim, as cursistas, ao planejarem atividades de ensino aos alunos de escolas, recorriam aos conhecimentos teórico-práticos desenvolvidos.

\subsection{Relatos de mudanças nas práticas}

Os artigos mencionam que o curso influenciou em uma atuação mais reflexiva e profissional das graduandas em Pedagogia, sendo que citam exemplos e casos de relatos das próprias alunas nos ambientes virtuais, destacando-se a elaboração dos portfólios de 
VII Congresso Brasileiro de Informática na Educação (CBIE 2018)

Anais dos Workshops do VII Congresso Brasileiro de Informática na Educação (WCBIE 2018)

aprendizagem apoiados em ferramentas digitais (blog). Nos portfólios as alunas realizaram análise das mudanças na atuação profissional e receberam comentários dos tutores, professores e colegas. Na análise, podem-se observar relatos que indicam a utilização na prática de sala de aula de algumas teorias e tecnologias usadas nos cursos, como, por exemplo, os projetos de aprendizagem a partir dos interesses dos alunos. No desenvolvimento dos projetos, os estudantes exploraram suas inquietações $\mathrm{e}$ curiosidades ao mesmo em que experimentaram o uso de tecnologias, como ambientes wiki e de construção de mapas conceituais.

Uma evidência de aprendizagem é que estou trabalhando um projeto de Estudos Sociais sobre escola. Havia planejado várias atividades para que as crianças relembrassem o nome da escola, descobrissem sua importância, onde fica situada (endereço), função exercida por cada funcionário, localização dos setores, no entanto surgiu uma questão de alguns alunos: "Por que nossa escola se chama 'EF'?"Através desta questão realizamos uma pesquisa sobre a história desta pessoa chamada "EF" e assim aprofundamos nossos conhecimentos sobre a escola. As crianças se sentiram motivadas em pesquisar, as descobertas geraram satisfação. Desta forma trabalhamos temas do interesse das crianças promovendo uma aprendizagem ativa e significativa (PORTO, 2013).

No relato de experiência, a graduanda faz uso dos questionamentos dos alunos para o desenvolvimento de um projeto por aprendizagem, em que as perguntas ou curiosidades do aluno pode gerar um trabalho de investigação. Em outros relatos, percebe-se a utilização das teorias desenvolvidas durante e após o curso, bem como das tecnologias experimentadas enquanto alunas, estabelecendo ligações com a realidade vivenciada nas escolas. A evolução das aprendizagens teóricas e a oportunidade de ressignificar o uso das tecnologias durante a formação, mostraram uma ampliação da visão do professor e modificar a práxis pedagógica.

Conforme o extrato de uma aluna do PEAD, um exemplo de articulação entre teoria e prática foi a aplicabilidade da tecnologia digital em sua sala de aula

Outra construção da aluna é a forma com que começa a lidar com as novas tecnologias. Ela passa a utilizar outras ferramentas, como, por exemplo, o scanner da escola, por não estar mais contente em apenas colocar gravuras prontas da Internet, começando a construir as suas próprias imagens, evidenciando o seu conhecimento e dos seus alunos. A aluna declara: "Antigamente eu dava minhas aulas e só usava o mimeógrafo sem pesquisas e agora meu trabalho parece ter mais beleza e produção, pesquisando na internet, recebendo emails, usando as imagens enfim um mundo rico a explorar que ainda estou me interagindo e aprendendo. Todo dia é um dia de novas aprendizagens com toda minha idade foi um grande desafio estudar e trabalhar a distância (MILLAN; CORTE REAL, 2011).

A articulação entre teoria e prática também ocorreu nas questões do uso da tecnologia, não apenas pela apropriação instrumental, mas pelo uso pedagógico dos recursos tecnológicos. Portanto, devido à maneira com que foram sendo instigados em relação à tecnologia e sua aplicabilidade na realidade escolar, verifica-se que, além de 
VII Congresso Brasileiro de Informática na Educação (CBIE 2018)

Anais dos Workshops do VII Congresso Brasileiro de Informática na Educação (WCBIE 2018)

mudanças nos paradigmas relacionados às questões metodológicas escolares, também ocorreu uma abertura para o uso de recursos tecnológicos e o enriquecimento das aulas nas escolas.

\section{Considerações finais}

Ao analisarmos as publicações científicas sobre o PEAD, identificamos evidências de contribuições das arquiteturas pedagógicas desenvolvidas no curso, principalmente a arquitetura "Portfólio de Aprendizagem", para a apropriação das teorias em articulação com as práticas docentes e, em decorrência dessa articulação, o desenvolvimento do pensamento reflexivo dos professores-alunos.

Para além das evidências relacionadas a evolução dos processos mais amplos de articulação teoria e prática, merecem destaque as mudanças especificamente relacionadas a concepções e usos das tecnologias digitais na educação. A superação da cultura do caderno e do material impresso, a evolução do domínio dos ambientes virtuais e a compreensão das suas possibilidades pedagógicas, desempenharam um papel importante para encorajar os alunos-professores a experimentarem novas propostas de trabalho nas escolas.

Ainda que não seja possível avaliar, a partir do foco desse estudo, a extensão do impacto do modelo de formação adotado para promover mudanças duradouras na atuação profissional dos alunos-professores, os dados analisados indicam que a perspectiva de implementação de arquiteturas pedagógicas na formação de professores também apresenta potencial para integrar tecnologias e currículos, modificando ao mesmo tempo a organização curricular e as formas de conceber e usar as tecnologias.

\section{Referências}

Aragón, R. (2016) Interação e mediação no contexto das arquiteturas pedagógicas para a aprendizagem em rede. In Revista de Educação Pública, v. 25, n. 59/1. UFMT, 2016.

Bardin, L. (2011) Análise de Conteúdo. Tradução de Luís Antero Reto, Augusto Pinheiro. São Paulo: Edições 70, 2011.

Brasil. Resolução CNE/CP n. 02, de 01/07/2015. Conselho Nacional de Educação. "RESOLUÇÃO CNE/CP N"2".

Carrasco, L.H.M; Trainott, S. T. (2013) Avaliação em EaD: diálogo com o ensino e a aprendizagem. RENOTE. Revista Novas Tecnologias na Educação, v. 11, p. 100112.

Carvalho, M.J; Nevado. R; Menezes, C. S. Arquiteturas Pedagógicas para a Educação a Distância. (2007) In Nevado. R; Carvalho, M.J; Menezes, C. S (org) Aprendizagem em Rede na Educação a Distância: Estudos e Recursos para Formação de Professores. Porto Alegre: Ricardo Lenz, 2007. 
VII Congresso Brasileiro de Informática na Educação (CBIE 2018)

Anais dos Workshops do VII Congresso Brasileiro de Informática na Educação (WCBIE 2018)

Costa, I. E.T; Magdalena, B. C. (2013). Seminário Integrador, no Polo de Alvorada: um estudo de caso. RENOTE - Revista Novas Tecnologias na Educação. Porto Alegre, v. 11, n. 2. (Edição Especial PEAD).

Freire, P. Pedagogia da Autonomia - Saberes necessários à prática educativa. (1996) São Paulo, Brasil: Paz e Terra (Coleção Leitura).

Freire, P. Por uma pedagogia da Pergunta / Paulo Freire, Antonio Faundez. (2011) Rio de Janeiro: Paz e Terra,. (Coleção Educação e comunicação, v. 15)

Global Alliance for Transforming Education". (1990) https://www.ties-edu.org/gate/ .

Lévy, P. As tecnologias da Inteligência- O futuro do pensamento na Era da Informática. (1990) Rio de Janeiro, Ed. 34.

Millan, G. L; Corte Real, L.M. Alfabetização Tecnológica Através da Construção de Blog. (2011) RENOTE. Revista Novas Tecnologias na Educação, v. 9, p. 1-18.

Nevado, R.; Menezes, C.; Vieira Júnior, R. Debate de Teses - Uma Arquitetura Pedagógica. (201) In: SBIE, 22.-WIE, 17., 2011, Aracaju. Anais... Aracaju: WIE,.p. 820-829.

Nóvoa, A. "O professor pesquisador e reflexivo" Entrevista concedida ao Programa Salto para o Futuro em 13-07-2001. Rio de Janeiro, TV Escola (MEC), Documento impresso.

Porto, L. S. Desenvolvendo o pensamento crítico através da EAD. (2013) RENOTE. Revista Novas Tecnologias na Educação, v. 11, n.2.

Universidade Federal Do Rio Grande Do Sul. (2006) "Projeto Pedagógico do Curso de Licenciatura em Pedagogia a distância" FACED-UFRGS.

Zeide, M, L. Charczuk, S.B, Araujo, A, And Aragón, R . "A construção do blog como portfólio de aprendizagem". (2013). RENOTE. Revista Novas Tecnologias na Educação, v.11, n.1. 